\title{
Anti-IL-23 therapy inhibits multiple inflammatory pathways and ameliorates autoimmune encephalomyelitis
}

\author{
Yi Chen, ${ }^{1}$ Claire L. Langrish,, ${ }^{1}$ Brent Mckenzie, ${ }^{1}$ Barbara Joyce-Shaikh, ${ }^{1}$ Jason S. Stumhofer, ${ }^{2}$ \\ Terrill McClanahan, ${ }^{3}$ Wendy Blumenschein, ${ }^{3}$ Tatyana Churakovsa, ${ }^{4}$ Justin Low, ${ }^{4}$ Leonard Presta, ${ }^{4}$ \\ Christopher A. Hunter, ${ }^{2}$ Robert A. Kastelein, ${ }^{1}$ and Daniel J. Cua ${ }^{1}$

\begin{abstract}
1Discovery Research, Schering-Plough Biopharma, Palo Alto, California, USA. ²Department of Pathobiology, School of Veterinary Medicine, University of Pennsylvania, Philadelphia, Pennsylvania, USA. ${ }^{3}$ Experimental Pathology and Pharmacology and ${ }^{4}$ Protein Engineering,
\end{abstract} \\ Schering-Plough Biopharma, Palo Alto, California, USA.
}

\begin{abstract}
IL-23 is a member of the IL-12 cytokine family that drives a highly pathogenic T cell population involved in the initiation of autoimmune diseases. We have shown that IL-23-dependent, pathogenic T cells produced IL-17A, IL-17F, IL-6, and TNF but not IFN- $\gamma$ or IL-4. We now show that T-bet and STAT1 transcription factors are not required for the initial production of IL-17. However, optimal IL-17 production in response to IL-23 stimulation appears to require the presence of T-bet. To explore the clinical efficacy of targeting the IL-23 immune pathway, we generated anti-IL-23p19-specific antibodies and tested to determine whether blocking IL-23 function can inhibit EAE, a preclinical animal model of human multiple sclerosis. Anti-IL-23p19 treatment reduced the serum level of IL-17 as well as CNS expression of IFN- $\gamma$, IP-10, IL-17, IL-6, and TNF mRNA. In addition, therapeutic treatment with anti-IL-23p19 during active disease inhibited proteolipid protein (PLP) epitope spreading and prevented subsequent disease relapse. Thus, therapeutic targeting of IL-23 effectively inhibited multiple inflammatory pathways that are critical for driving CNS autoimmune inflammation.
\end{abstract}

\section{Introduction}

MS is a chronic autoimmune disorder affecting an estimated 2.5 million people worldwide. The pathological hallmarks for MS include perivascular $T$ cell inflammation and disseminated demyelinating lesions. EAE is an inflammatory autoimmune disease, inducible in mice, that resembles human MS. As in MS, autoaggressive $\mathrm{T}$ cells traffic to the brain and spinal cord and induce CNS demyelination, leading to paresthesia, paraparesis, neuritis, and ataxia $(1,2)$. Because of its similarity to human MS, EAE has been used as an animal model for proof of concept studies for MS therapy.

Cytokines play a pivotal role in the establishment and maintenance of autoimmune diseases. Numerous studies have established IL-12 as an important factor for the differentiation of naive $\mathrm{T}$ cells into IFN- $\gamma$-producing Th1 cells, which are essential for cell-mediated immunity, including antimicrobial responses and tumor suppression (3-5). Over the past decade, IL-12-driven Th1 cells were also shown to be essential for the induction of autoimmune diseases, primarily through investigations using IL-12p40-/- mice and IL-12p40-neutralizing antibodies (6-13). However, mice lacking certain components of the Th1/IFN- $\gamma$ pathway (IL-12 $\mathrm{p}^{-/-} 5^{-,}$IL-12 $\beta 1^{-/-}$, IFN- $\gamma^{-/-}$, IFN- $\gamma \mathrm{R}^{-/-}$, and STAT1; $R$, receptor) are highly susceptible to inflammatory autoimmune diseases, indicating that these regulatory factors are not always required for disease induction (14-19). Yet other Th1 signaling

Nonstandard abbreviations used: DLN, draining lymph node; MOG, myelin oligodendrocyte glycoprotein; PLP, proteolipid protein; R, receptor.

Conflict of interest: Y. Chen, C.L. Langrish, B. Mckenzie, B. Joyce-Shaikh, T. McClanahan, W. Blumenschein, T. Churakovsa, J. Low, L. Presta, R.A. Kastelein, and D.J. Cua are employed by Schering-Plough Corp. J.S. Stumhofer and C.A. Hunter have declared that no conflict of interest exists.

Citation for this article: J. Clin. Invest. 116:1317-1326 (2006). doi:10.1172/JCI25308. components, such as STAT4 and T-bet, are essential for autoimmune pathogenesis $(19,20)$. These findings suggest that another $\mathrm{T}$ cell population in addition to the IFN- $\gamma$-producing T cells may also play a role in CNS autoimmune pathogenesis. The recent discovery of IL-23 - a cytokine that shares the p40 subunit with IL-12 - has since prompted reevaluation of the role of IL-12/Th1 response in autoimmunity $(21,22)$. Using genetic approaches, studies have demonstrated that IL-23 rather than IL-12 is required for the development of spontaneous as well as adjuvant-induced autoimmune diseases such as EAE, collagen-induced arthritis (16, $17,23-25)$, and inflammatory bowel disease (26). It has recently been shown that while IL-12 is required for the development of IFN- $\gamma$-producing T cells, IL-23 promotes the expansion of a population of encephalitogenic $\mathrm{T}$ cells that produces IL-17A, IL-17F, IL-6, and TNF but not IFN- $\gamma$ or IL-4, suggesting that these cells represent a novel $\mathrm{T}$ cell subset (25). We now show that these IL-17-producing cells are not dependent on T-bet and STAT1 transcription factor and that functional blockade of IL-23 can prevent induction of EAE and reverse established disease. We also studied the mechanisms of protection of IL-23-specific blockade during multiple stages of disease pathogenesis. Our results show that early anti-IL-23p19 treatment reduces encephalitogenic T cell and inflammatory myeloid cell invasion into the CNS and that treatment during active disease prevents epitope spreading of $\mathrm{CD}^{+} \mathrm{T}$ cells and inhibits subsequent disease relapse.

\section{Results}

Anti-IL-23 treatment prevents acute and relapsing EAE. IL-23-deficient mice are highly resistant to autoimmune diseases, including EAE, collagen-induced arthritis, and inflammatory bowel disease (23-25). However, this genetic resistance to autoimmune inflammation does not predict whether neutralizing the function of IL-23 can 
A
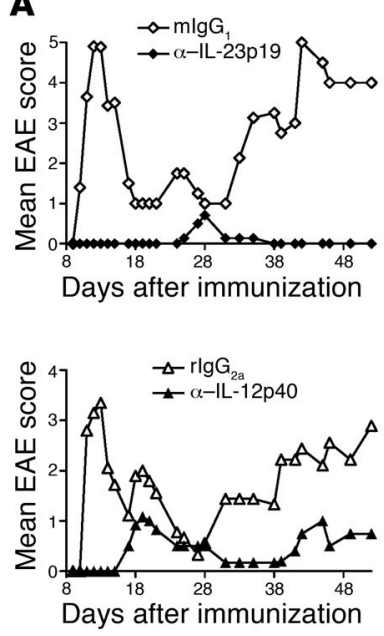

B

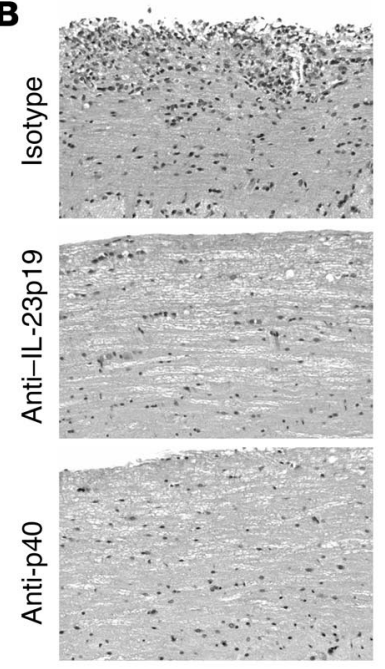

\section{Figure 1}

Anti-IL-23 treatment inhibits acute EAE. (A) Average clinical score of mice treated with $1 \mathrm{mg}$ of anti-IL-23p19 (clone MB74) or anti-IL12p40 (clone $\mathrm{C} 17.8$ ) injected at day -1 and day 6 of EAE priming. One of 4 experiments is shown. Disease incidence and average disease onset of all mice are shown in Table 1. (B) Routine H\&E histology of spinal cords from antibody-treated mice taken at days 30-40 of immunization. Original magnification, $\times 200$. Representative micrographs of antiIL-23p19 and -p40 treated groups show no inflammation in the white matter of the CNS. Rat $\lg \mathrm{G}_{2 \mathrm{a}}\left(\mathrm{rlgG}_{2 \mathrm{a}}\right)$ isotype control group shows infiltration of inflammatory cells in the lumbar region of the spinal cord. Mouse $\operatorname{lgG}_{1}\left(\mathrm{mlgG}_{1}\right)$ controls showed similar levels of CNS inflammatory cellular infiltration (not shown). ameliorate ongoing disease. To determine the therapeutic efficacy of IL-23 blockade, we developed neutralizing anti-IL-23p19 antibodies that specifically inhibit the function of IL-23 but not IL-12 (Supplemental Figure 1; supplemental material available online with this article; doi:10.1172/JCI25308DS1) and tested the capacity of these mAbs to inhibit EAE. We also compared the efficacy of anti-IL-23p19 mAbs with anti-p40 mAbs, which neutralize the function of both IL-12 and IL-23. SJL mice were immunized with proteolipid protein $139-151$ ( PLP $\left._{139-151}\right)$ peptide in CFA and injected with anti-IL-23p19 mAbs or anti-p40 mAbs at 1 day before and 6 days after immunization. Anti-IL-23p19 treatment effectively blocked both acute disease and EAE relapse, and histopathology showed absence of inflammatory cells in the spinal cord (Figure 1 and Table 1). Consistent with previous reports, anti-p40 treatment was also remarkably effective $(6,8,27)$. Isotype treatment groups showed $100 \%$ EAE incidence and severe inflammatory cell infiltration into the spinal cord. This result is consistent with our previous studies demonstrating that targeted genetic disruption of IL-23 results in complete resistance to inflammatory autoimmune diseases (23-25).

Anti-IL-23 therapy inhibits T cell and inflammatory macrophage invasion of the CNS. To understand how IL-23 regulates inflammatory $\mathrm{T}$ cell and macrophage recruitment into the CNS, we analyzed the cytokine production profiles of mononuclear cells isolated from the brain and spinal cord before and after EAE onset. A normal CNS has undetectable to very few $\mathrm{CD} 4^{+} \mathrm{T}$ cells and CD $45^{\text {hi }} \mathrm{CD} 11 \mathrm{~b}^{+}$myeloid cells $(28,29)$. During the course of EAE, $\mathrm{T}$ cells and inflammatory macrophages invade the CNS and produce a range of inflammatory cytokines $(23,28)$. Ex vivo analysis of $\mathrm{T}$ cells infiltrating the CNS showed that, in addition to IFN- $\gamma-$ producing Th 1 cells, IL-17-producing $\mathrm{CD}^{+} \mathrm{T}$ cells were also present (Figure 2A and Table 2) (25). To elucidate the roles of IFN- $\gamma$, IL-17, and IL-23 in CNS inflammation, mice were treated with neutralizing antibodies at day -1 and day 6 after PLP-CFA immunization. Anti-IFN- $\gamma$-treated mice had a severe form of the disease, with a $43 \%$ mortality rate. Anti-IL-17 treatment partially ameliorated EAE while anti-IL-23p19 completely protected mice from disease (Figure 2, B and C). Just before disease onset, the IL-17 serum level was highly elevated in EAE-susceptible IFN- $\gamma$ treated mice. In contrast, the IL-17 level was near the limit of detection in the anti-IL-23p19-treated mice (Figure 2D). Even though IFN- $\gamma$ mRNA can be detected in the CNS during acute EAE (days 12 to 16 ) (30), our assay was not sensitive enough to detect serum IFN- $\gamma$ at this time point (not shown).

Histopathology of lumbar spinal cords from an anti-IL-23p19treated group had undetectable or a few scattered leukocytes, as assessed by hematoxylin staining. Anti-IFN- $\gamma$-treated mice showed intense inflammatory infiltration (Figure 2E). The antiIL-17 antibody-treated mice showed an intensity of CNS-infiltrating cells similar to that of the isotype control group. In order to determine the number and the cytokine profile of CNS-infiltrating cells during EAE, we isolated mononuclear cells from the brain and spinal cord of mice before and after disease onset. Flow cytometric analysis showed that 7 days after myelin oligodendrocyte glycoprotein (MOG) priming (3 to 4 days before expected onset of clinical disease), anti-IL-23p19-treated mice showed a number (7000 to 9000) of IFN- $\gamma$-producing cells similar to that of the isotype controls (Table 2). In contrast, the number of

\section{Table 1}

Administration of anti-IL-23 prevented myelin antigen-induced EAE

\begin{tabular}{lccc}
\hline & & Clinical EAE & \\
& Incidence & $\begin{array}{c}\text { Mean day } \\
\text { of onset }\end{array}$ & $\begin{array}{c}\text { Mean maximal } \\
\text { score }\end{array}$ \\
Anti-IL-23p19A & $4 / 50(8 \%)$ & $23.25 \pm 1.49$ & $0.32 \pm 0.16^{B}$ \\
mlgG $_{1}$ & $27 / 31(87 \%)$ & $11.37 \pm 0.31$ & $3.53 \pm 0.34$ \\
Anti-IL-12p40 & $6 / 29(21 \%)$ & $20.50 \pm 3.0$ & $1.03 \pm 0.40^{\mathrm{C}}$ \\
rlgG $_{2 \mathrm{a}}$ & $10 / 10(100 \%)$ & $11.20 \pm 0.2$ & $4.3 \pm 0.54$
\end{tabular}

Mice were immunized with PLP PI3-151 $_{13}$ and treated with pertussis toxin at day 0 . Assessment of clinical EAE includes the number of mice that developed disease, the mean day of disease onset \pm SEM among mice with $E A E$, and the mean clinical disease grade \pm SEM of each treatment group. The results of 4 separate experiments are shown. AMice were injected with $1 \mathrm{mg}$ of indicated anti-cytokine mAbs 1 day before and 6 days after EAE priming. ${ }^{\mathrm{B} P}<0.01$, comparing anti-IL-23p19 versus $\mathrm{mlgG}_{1}$ isotype $\mathrm{mAb}$-treated group by Mann-Whitney $U$ test; $C P<0.01$, comparing anti-IL-12p40 versus IgG $_{2 a}$ isotype mAb-treated group by Mann-Whitney $U$ test. 

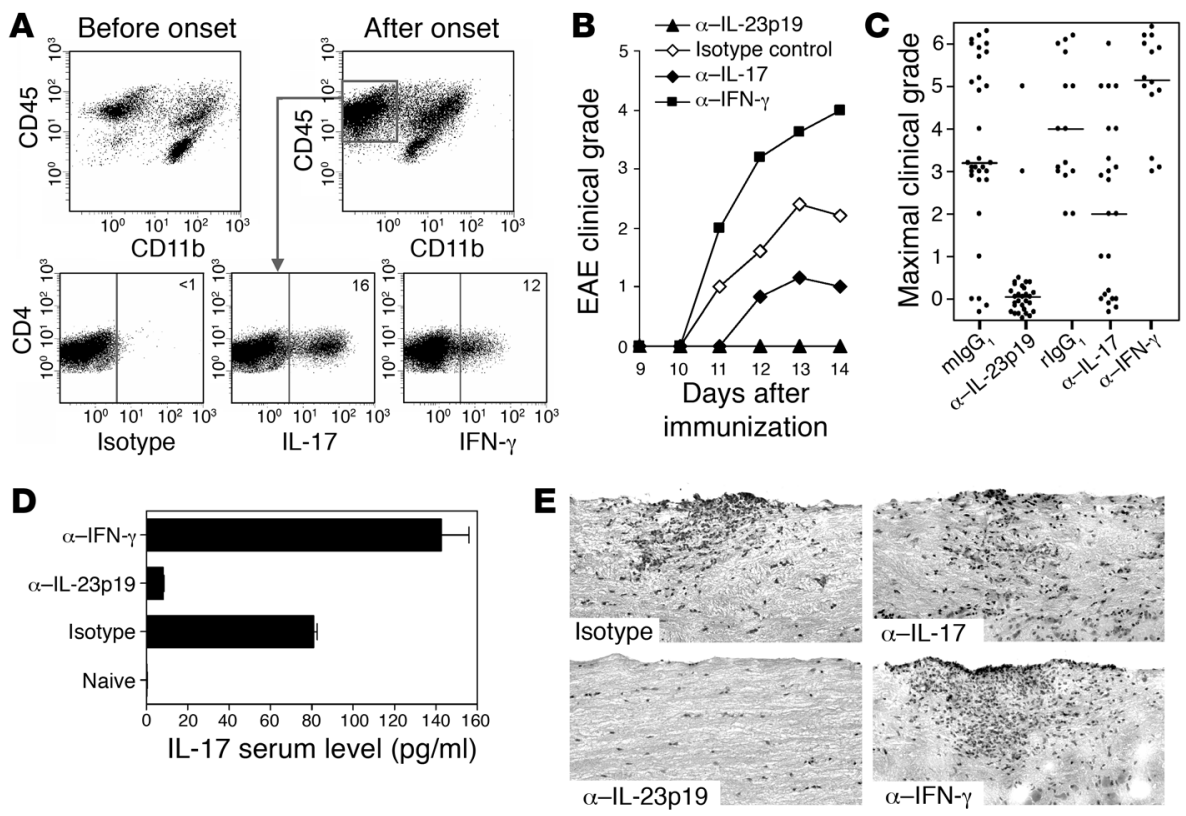

Figure 2

Blockade of IL-23 and IL-17 but not IFN- $\gamma$ protects from EAE. (A) Phenotypic and intracellular cytokine analysis of CNS-infiltrating cells in the brain and spinal cord of WT mice before and after EAE onset. Intracellular IL-17 and IFN- $\gamma$ production by CD4 ${ }^{+}$CNS-infiltrating cells isolated from PLP-immunized SJL mice immediately following ex vivo stimulation with PMA/ionomycin for 4 hours prior to analysis. Data are representative of at least 5 independent experiments. (B) Average clinical score of mice $(n \geq 5)$ treated with $1 \mathrm{mg}$ of indicated mAbs injected at day -1 and day 6 of immunization. Data are representative of at least 3 experiments. (C) Filled circles represent peak severity of clinical disease for individual mice of the indicated antibody treatment group. Data for the anti-IFN- $\gamma$ treatment group are compiled from 3 separate experiments whereas data from the anti-IL-23p19 and anti-IL-17 groups are from at least 5 experiments. (D) Mice were treated with anti-IL-23p19 or anti-IFN- $\gamma$ at day -1 and day 6 of immunization. Serum was prepared for IL-17 ELISA 2 days before expected onset. The limit of detection for serum IL-17 is $10 \mathrm{pg} / \mathrm{ml}$. Results shown are averages of 5 mice per treatment group \pm SEM and are representative of 2 experiments. (E) Routine H\&E histology of spinal cords from antibody-treated mice taken at peak disease. Representative micrograph of anti-IL-23p19 treated mice shows no inflammation in the white matter of the CNS. Isotype control mAb-, anti-IL-17-, and anti-IFN- $\gamma$-treated mice show intense infiltration of inflammatory cells in the lumbar region of the spinal cord.

IL-17-producing cells was reduced in the anti-IL-23p19 treatment group (1800) compared with isotype controls (4000-6000). By day 9 after MOG priming (1 day before expected disease onset), the total number of $\mathrm{CD}^{+} \mathrm{T}$ cells and inflammatory macrophages in the EAE-resistant anti-IL-23p19 treatment group was less than that of isotype controls (Figure $3 \mathrm{~A}$ and Table 2). Accordingly, the number of IL-17, IFN- $\gamma$, and TNF producers was also reduced by 2 - to 5 -fold compared with isotype controls (Table 2). By day 12 after MOG priming (2 days after onset of clinical disease in control antibody groups), the EAE-resistant anti-IL-23p19-treated group had 6-fold fewer IL-17-producing T cells $(15,000)$ and 2 -fold fewer IFN- $\gamma(30,000)$ and TNF $(210,000)$ producers (Table 2 and Figure 3 , B-D). In contrast, the EAE-susceptible anti-IFN- $\gamma$-treated group had dramatically more inflammatory cells than the control group. There were 340,000 IL-17-producing cells, 190,000 IFN- $\gamma$-producing cells, and 1,100,000 TNF-producing $\mathrm{CD}^{+} \mathrm{T}$ cells per CNS of anti-IFN- $\gamma$-treated mice (Table 2). It is likely that this large-scale proinflammatory $\mathrm{T}$ cell invasion may correlate with increased disease severity. These results suggest that IL-23 may promote expansion and/or recruitment of inflammatory cells into the CNS. On the other hand, although IFN- $\gamma$ does contribute to disease during the initiation of CNS inflammation, this cytokine also appears to play a critical feedback regulatory role by reducing the number of pathogenic cells within the CNS. This is consistent with studies demonstrating the proapoptotic function of IFN- $\gamma$ (31). The anti-IL-17-treated group had a number and percentage of cytokineproducing cells similar to those of the isotype control groups, suggesting that neutralizing the function of IL-17 does not alter the capacity of $\mathrm{T}$ cells and inflammatory macrophages to invade the CNS but that IL-17 might serve as an effector cytokine working downstream of IL-23. Taken together, these results suggest that the mechanism of protection of anti-IL-23 therapy is associated with decreased serum levels of IL-17 and a reduced number of CNS-infiltrating inflammatory macrophages as well as IL-17-, IFN- $\gamma$-, and TNF-producing $\mathrm{T}$ cells. Thus, targeting the function of IL-23 results in profound inhibition of multiple inflammatory pathways.

IL-23 drives a different signaling pathway. We have shown that IL-23 appears to induce a $\mathrm{T}$ cell population that shares many functional characteristics with IFN- $\gamma$-producing Th 1 cells. As few as 100,000 IL-17-producing cells are capable of inducing CNS inflammatory responses leading to autoimmune encephalomyelitis (25). To explore the signaling pathways of IL-12- versus IL-23dependent $\mathrm{T}$ cells, we analyzed the function of T-bet and STAT1, which are known to promote type I immune responses. Lymph node cells from naive T-bet-deficient or WT control mice were cultured with anti-CD3 in the presence or absence of IL-23. IL-23p19-deficient lymph node cells do not produce IL-17 following antigenic or anti-CD3 stimulation (data not shown) (24). In contrast, T-bet-deficient cells produced substantial levels (3000 to 4800 pg) of IL-17 following anti-CD3 stimulation. However, exogenous IL-23 did not further enhance IL-17 production, suggesting that T-bet may enhance IL-23-mediated IL-17 secretion (Figure 4A). Next, we compared the expression of T-bet in IL-12-driven Th1 cells and IL-23-driven IL-17-producing T cells. Cells cultured in the presence of IL-12 expressed higher levels of T-bet mRNA than IL-23 cultured cells (Figure 4B). In addition, IFN- $\gamma$-producing Th1 cells expressed 5-fold more T-bet and 100fold more TIM3, a Th1-specific membrane protein that regulates autoimmunity (32), compared with IL-17-producing cells (Figure 4C). These results indicate that T-bet is present in IL-17-producing cells. However, during differentiation of IL-17-producing cells, T-bet expression and function are reduced compared with Th1 cells. To determine whether STAT1 is also required for IL-23 to drive IL-17 production, lymph node cells from naive STAT1-defi- 


\section{Table 2}

Number of cytokine-producing CD4+ cells per CNS of EAE-primed mice

\begin{tabular}{|c|c|c|c|c|}
\hline & Treatment & IL-17 & IFN- $\gamma$ & TNF \\
\hline \multicolumn{5}{|c|}{ Before EAE onset } \\
\hline \multirow[t]{5}{*}{ Day $7^{A}$} & $r \lg G_{1}$ & 4,100 & 7,600 & 107,200 \\
\hline & $\mathrm{mlg}_{1}$ & 6,000 & 6,500 & 118,000 \\
\hline & anti-p19 & 1,800 & 9,000 & 58,200 \\
\hline & anti-IL-17 & 9,600 & 1,550 & 48,500 \\
\hline & anti-IFN- $\gamma$ & 2,250 & 2,250 & 49,750 \\
\hline \multirow[t]{5}{*}{ Day 9} & $\mathrm{rlg}_{1}$ & 50,935 & 23,350 & 140,000 \\
\hline & $\mathrm{mlg}_{1}$ & 19,900 & 23,980 & 112,500 \\
\hline & anti-p19 & 6,150 & 12,050 & 63,500 \\
\hline & anti-IL-17 & 31,200 & 32,200 & 156,000 \\
\hline & anti-IFN- $\gamma$ & 22,400 & 21,050 & 90,500 \\
\hline \multicolumn{5}{|c|}{ After EAE onset } \\
\hline \multirow[t]{5}{*}{ Day $12^{B}$} & $r \lg G_{1}$ & 110,200 & 76,950 & 535,800 \\
\hline & $\mathrm{mlg}_{1}$ & 88,000 & 72,450 & 510,300 \\
\hline & anti-p19 & 15,300 & 30,600 & 216,900 \\
\hline & anti-IL-17 & 55,050 & 65,650 & 434,900 \\
\hline & anti-IFN- $\gamma$ & 338,500 & 192,400 & $1,128,500$ \\
\hline
\end{tabular}

The total number of cytokine-producing cells in the brain and spinal cord of $\mathrm{mAb}$-treated mice was determined by intracellular cytokine FACS analysis. CNS-infiltrating cells from 3-4 mice from each treatment group were pooled and stimulated ex vivo with PMA/ionomycin for 4 hours prior to intracellular cytokine analysis. Results are representative of 2 independent experiments. No cytokine-producing CD4+ cells were detected in the CNS of naive mice. Mice were injected with $1 \mathrm{mg}$ of indicated anti-cytokine mAbs 1 day before and 6 days after MOG-CFA priming. ${ }^{A}$ Days after MOG-CFA immunization. ${ }^{B}$ Disease onset occurred on days 10 to 11 after immunization.

cient or WT control mice were cultured with anti-CD3 in the presence or absence of exogenous IL-23. Surprisingly, STAT1-deficient cells produced high levels of IL-17 following anti-CD3 stimulation (Figure 4A). Addition of exogenous IL-23 further enhanced IL-17 production in the STAT1-deficient cells. These results suggest that, while STAT1 is important for IFN- $\gamma$ signaling, it is not a critical factor for the IL-23/IL-17 immune pathway.

Therapentic targeting of IL-23 inhibits spreading of PLP epitopes and prevents $E A E$ relapse. We have demonstrated that administration of anti-IL-23p19 mAbs blocked the invasion of inflammatory cells into the CNS and prevented EAE. Next, we determined whether targeting IL-23 can suppress and reverse ongoing disease. AntiIL-23p19 treatment given just before (not shown) or on the day of disease onset (Figure 5A and Table 3) did not inhibit the severity of acute disease but completely prevented EAE relapse. Antip40 treatment given on the day of disease onset also blocked EAE relapse but not acute disease. These results suggest that targeting IL-23 may influence regulatory mechanisms affecting development and/or recruitment of inflammatory cells to the CNS but cannot inhibit ongoing inflammatory effector mechanisms within the CNS. To understand how anti-IL-23 therapy inhibited disease relapse, we determined whether IL-23 blockade impeded PLP epitope spreading. In SJL mice, recent studies have shown that following PLP $\mathrm{P}_{139-151}$ immunization, 1 of the $\mathrm{T}$ cell epitopes that arises during disease relapse is directed against PLP $_{178-191}$ (33). Therefore we tested $\mathrm{T}$ cell responses to $\mathrm{PLP}_{139-151}$ and $\mathrm{PLP}_{178-191}$ during initial EAE (day 11) and disease relapse (day 30). Mice were treated with anti-IL-23p19 or control mAbs just before disease onset. Draining lymph node (DLN) cells and CNS-infiltrating cells isolated from both the anti-IL-23p19 and isotype control mAb-treated groups showed PLP ${ }_{139-151}$ but not PLP $_{178-191}$ response during the initial EAE attack (Figure 5B). In contrast, during disease relapse, the dominant response of CNS-infiltrating $\mathrm{T}$ cells from the isotype control group was $\mathrm{PLP}_{178-191}$ whereas the DLN-T cell response was specific for PLP $_{139-151}$ but not PLP $_{178-191}$ (Figure 5B). This indicates that epitope spreading was restricted to the CNS and did not occur in the periphery, consistent with previous results (33). Strikingly, mice treated with anti-IL-23p19 mAbs (day 8) showed a vigorous CNS PLP $_{139-151}$ response during the initial acute disease (day 11) but a complete lack of PLP P $_{139-151}$ response and epitope spreading to PLP $_{178-191}$ (day 30). Thus, therapeutic targeting of IL-23 suppressed reactivation of the local response to $\mathrm{PLP}_{139-151}$ as well as epitope spreading to $\mathrm{PLP}_{178-191}$, resulting in complete inhibition of disease relapse.

To further demonstrate the efficacy of anti-IL-23p19 therapy for relapse-remitting CNS inflammation, we initiated antibody treatment during recovery from acute EAE. Anti-IL-23p19 treatment at this time point significantly prevented disease relapse whereas isotype-treated mice had multiple rounds of EAE relapse (Figure $6 \mathrm{~A}$ and Table 3). Anti-p40 treatment, which inhibits both IL-12 and IL-23, also completely prevented disease relapse. In addition, anti-IL-17 treatment also delayed EAE relapse and reduced disease incidence and severity. Fifty days after immunization, spinal cord histopathology showed that both anti-IL-23p19- and antip40-treated groups had significantly fewer inflammatory foci than the isotype control groups (Table 3). However, even though anti-IL-17 treatment blocked EAE relapse, it did not significantly reduce the number of infiltration foci, suggesting that this treatment does not alter inflammatory cell migration and/or expansion but may downregulate the effector function of inflammatory cells within the CNS.

We also analyzed proinflammatory gene expression of spinal cords following anti-IL-23p19, anti-IL-12/23p40, and anti-IL-17 therapy. Both anti-IL-23p19 and anti-IL-12/23p40 antibody treatment significantly blocked the induction of IFN- $\gamma$, IL- $1 \beta$, IL-6, IL-17, TNF, CCL6, MIG, and IP-10 gene expression compared with isotype-treated mice (Figure 6B). Anti-IL-17 treatment specifically reduced expression of IL-1, IL-6, and CCL6. Anti-IL-12/23p40 treatment but not anti-IL-23p19 treatment reduced mRNA expression of osteopontin (OPN). Specific blockade of IL-23 also resulted in a 10- to 100 -fold reduction of macrophage- and dendritic cell-associated genes such as MDC, MCP-1, CXCL1, CXCL2, CCR1, MHC class II, CD11b, Mac 2, F4/80, CD86, CD14, TREM2, MYD88, and NADPhox gp91 compared with spinal cords of control-treated mice (not shown). These results suggest that targeting the IL-23/IL-17 immune pathway can prevent disease relapse in mice that already have active CNS lesions.

\section{Discussion}

The study of IL-12 and IL-23 regulation of immune responses has yielded important clues to identifying additional players in cellular immunity. We now know that, in addition to the IFN- $\gamma-$ producing Th1 cells, there is a second population of T cells that can drive autoimmune pathologies. Due to its prominent production of IL-17 and its proinflammatory nature, this novel T cell population has been termed $\operatorname{Th}_{\mathrm{IL}-17}(25,34)$, Th17 cells $(35,36)$, or inflammatory Th cells (37). An important question that needs to be addressed is the lineage relationship between the IFN- $\gamma-$ 

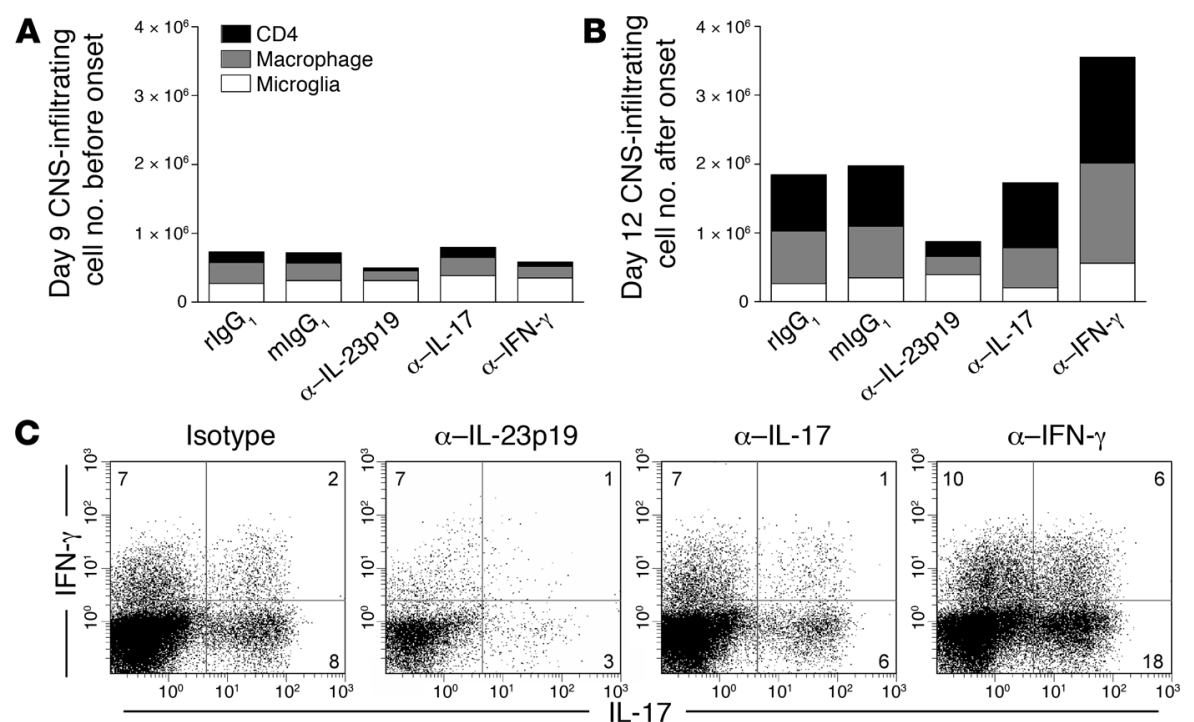

D
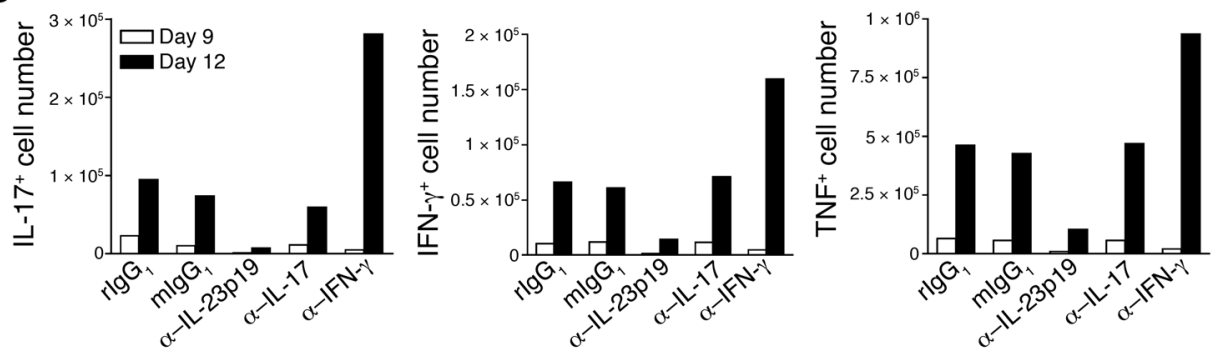

\section{Figure 3}

Anti-IL-23p19 mAbs inhibit CNS infiltration of IL-17-, IFN- $\gamma$ - and TNF-producing CD4+ $T$ cells. The total number of $\mathrm{CD}^{+} \mathrm{T}$ cells, CD45 hi CD11 b macrophages, and $C D 45^{\circ} \mathrm{CD} 11 \mathrm{~b}^{+}$ microglia in the brain and spinal cord of antibody-treated mice was determined by FACS analysis. CNS mononuclear cells were isolated either $(\mathbf{A})$ 2 days before expected EAE onset or (B) 2 days after disease onset. (C) Intracellular expression of IL-17 and IFN- $\gamma$ in $\mathrm{CD}^{+} \mathrm{T}$ cells isolated from the CNS at peak disease. IL-17 and IFN- $\gamma$ production by CD4+ CNS-infiltrating cells were determined following immediate ex vivo stimulation with PMA/ionomycin for 4 hours prior to intracellular cytokine analysis. Data are representative of 2 independent experiments. (D) Cells isolated from the brains and spinal cords of 3 mice were pooled for intracellular cytokine analysis. Data are the average number of IL-17-, IFN- $\gamma-$, and TNF-producing CNS-infiltrating $T$ cells per animal. All cell samples were stimulated with PMA/ionomycin for 4 hours prior to analysis. All plots were gated on live $\mathrm{CD} 4{ }^{+} \mathrm{T}$ cells and are representative of 2 independent experiments. producing Th1 and Th $\mathrm{h}_{\mathrm{IL}-17}$ cells. There is agreement that IL-12 activation of STAT4 is necessary for optimal differentiation of naive $\mathrm{T}$ cells into IFN- $\gamma$-producing Th1 cells. IFN- $\gamma$ then activates the STAT1 transcription factor, which enhances T-bet expression. T-bet activation is required for optimal IL-12R $\beta 2$ expression and IL-12 responsiveness in Th1 cells $(19,38-40)$. One crucial question is why STAT4 and T-bet appear to be important for autoimmune disease induction while IL-12, IFN- $\gamma$, and STAT1 signaling are not always required. The discovery of the IL-17-producing T cell population that does not depend on IL-12-IFN- $\gamma$-STAT1 signaling has provided a partial explanation for the observed discrepancy in autoimmune disease models. We now know that STAT1 activation is not required for T cell response to IL-23 and subsequent IL-17 production (Figure 4). As the cells mature in the presence of IL-23, both T-bet and TIM3 - a potent Th1 cell-associated regulatory molecule $(32,41)$ - may be repressed due to the absence of IFN- $\gamma$ and STAT 1 signaling. While IL-23p19-deficient mice do not produce detectable levels of IL-17 $(24,25)$, lymph node cells from both T-bet-deficient and WT mice produce similar levels of IL-17 (Figure 4A), consistent with a recent report that IL-17-producing cells are present in T-bet-deficient mice (37). The observation that IL-17-producing cells are present in EAE-resistant T-bet-deficient mice suggests that $\mathrm{Th}_{\mathrm{IL}-17}$ cells are not sufficient to induce disease and that other T-bet-dependent factors and/or cell populations have important roles in disease pathogenesis.

We also observed that addition of IL-23 to T-bet-deficient lymph node cell cultures did not further increase IL-17 production (Figure 4), consistent with the notion that T-bet may influence IL-23 responsiveness during early development (42). In addition, the presence of T-bet in cells is reminiscent of the discovery that both T-bet and GATA-3 are present in T cells during early differentiation and that T-bet interferes with the function of GATA-3, leading to preferential Th1 lineage commitment (43). These findings suggest that T-bet may have complex regulatory roles - both positive and negative effects - during $\mathrm{Th}_{\mathrm{IL}-17}$ development. Future work will elucidate how T-bet regulates transcription factors that promote $\mathrm{Th}_{\mathrm{IL}-17}$ lineage development.

The current study suggests that one of the mechanisms of protection of anti-IL-23p19 therapy is associated with inhibition of encephalitogenic T cells. Intracellular cytokine analysis of draining lymph node cells from PLP-primed mice indicated that antiIL-23p19 treatment reduced the number of IL-17-producing cells but not IFN- $\gamma$-producing cells. Addition of anti-IL-23p19 mAbs to PLP $139-151^{-}$stimulated DLN cell cultures also specifically reduced the percentage of IL-17-producing cells (Supplemental Figure 2). During the early phase of EAE ( 3 to 4 days before clinical disease onset), there were fewer IL-17-producing cells entering the CNS of anti-IL-23p19-treated mice (Table 2). At this time point, similar numbers of IFN- $\gamma$-producing cells were found in both groups of mice. This specific reduction of CNS-infiltrating IL-17-producing cells may be explained by the hypothesis that anti-IL-23p19 treatment directly inhibited the expansion of IL-17-producing T cells. This is consistent with recent studies showing that IL-23 is required for the expansion of pathogenic IL-17-producing T cells (25). Furthermore, the IFN- $\gamma /$ STAT1 signaling pathway is a potent negative regulator of IL-23/IL-17 immune responses $(36,37)$.

Although CNS antigen-specific IFN- $\gamma$-producing Th1 cells can transfer EAE to naive recipient mice, administration of anti-IFN- $\gamma$ 
A
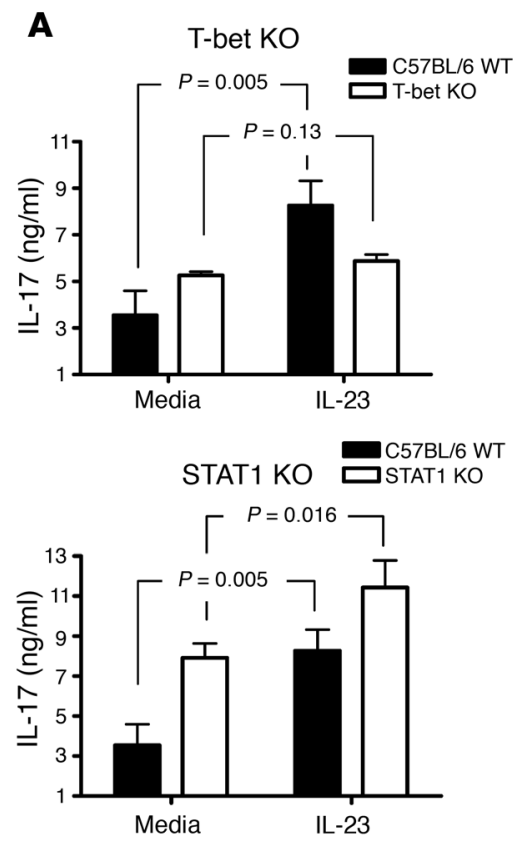

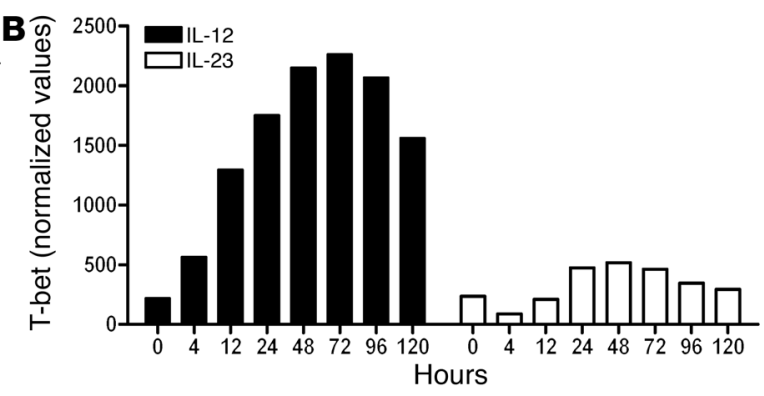

C
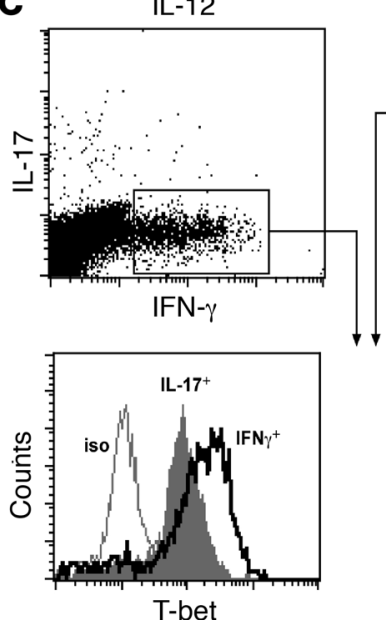

IL-23
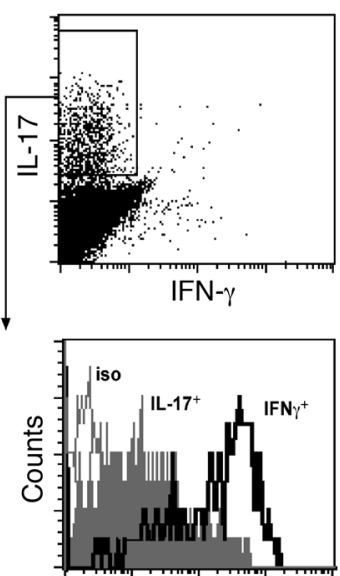

TIM3

Figure 4

T-bet and TIM3 expression in IFN- $\gamma$ - and IL-17-producing T cells. (A) Lymph node cells from naive C57BL/6 WT mice and T-bet- or STAT1deficient mice were stimulated with soluble anti-CD3 for 48 hours in the presence or absence of IL-23. IL-17 levels in the culture supernatant were measured by ELISA. Data are mean cytokine production \pm SD of separate lymph node cultures from 3 mice and are representative of

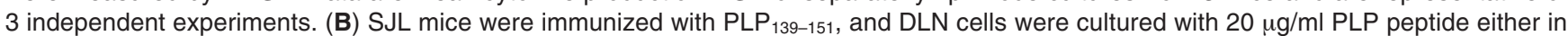
Th1-promoting conditions (IL-12 with blocking anti-IL-17 and anti-IL-23p19) or Th17-promoting conditions (IL-23 with blocking anti-IFN- $\gamma$ and anti-IL-12p35). Cells were collected at $0,4,12,24,48,72,96$, and 120 hours after culture. mRNA for T-bet was quantified by real-time PCR (TaqMan) and normalized to ubiquitin. Data are representative of 3 independent experiments. (C) At 96 hours, IL-17-and IFN- $\gamma-$ producing CD4+ T cells were identified by intracellular cytokine staining. T-bet and TIM3 expression were determined by costaining of cytokine-positive cells for T-bet (clone 4B10) or TIM3 (clone 8B.2C12).

mAbs paradoxically induced EAE exacerbation (Figures 2 and 3) (44), suggesting that IFN- $\gamma$ could have a downregulatory role during chronic autoimmune inflammation. IFN- $\gamma$ has been shown to decrease IL-1 and IL-8 production and increase IL-1Ra, IL-18BP, and SOCS expression (45). The current study suggests that blocking the function of IFN- $\gamma$ results in an increased number of IL-17, IFN- $\gamma$, and TNF-producing cells in the CNS, leading to disease exacerbation. This result is consistent with the requirement of IFN- $\gamma$ for activation-induced cell death of Th1, Th2, and probably $\mathrm{Th}_{\mathrm{IL}-17}$ cells. Refaeli et al. showed that IFN- $\gamma$ and STAT 1 transcription factor are required for caspase-8-dependent apoptosis and suggest that the IFN- $\gamma$ signaling pathway is critical for controlling the expansion and persistence of T cell responses (31). Novelli et al. demonstrated in the human system that both Th1 and Th2 cells express IFN- $\gamma$ receptor and are sensitive to apoptosis mediated by IFN- $\gamma$-induced FasL expression (46). More recently, 2 studies demonstrated that IFN- $\gamma$ strongly suppresses the development of $\mathrm{Th}_{\mathrm{IL}-17}$ cells $(36,37)$. Thus, IFN- $\gamma$ has a number of important regulatory roles during chronic inflammation.

We observed that therapeutic targeting of IL-23 during active EAE inhibited subsequent disease relapses. Two possible mecha- nisms that may explain this observation include inhibition of encephalitogenic epitope spreading and enhanced generation of Tregs. Miller and coworkers have recently demonstrated that local APC and/or dendritic cell activation of naive T cells within the CNS is required for encephalitogenic epitope spreading (33). Our study showed that anti-IL-23p19 treatment during active disease

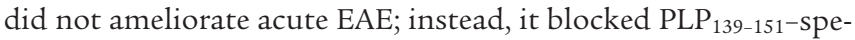
cific T cells within the CNS and epitope spreading to additional encephalitogenic epitopes such as $\mathrm{PLP}_{178-191}$. Interestingly, the protected mice still had $\mathrm{PLP}_{139-151}$-reactive cells in the peripheral lymphoid tissues. This finding suggests that the therapeutic action of anti-IL-23 for ongoing EAE is likely to occur within the target organ. We also determined whether Tregs are enhanced in anti-IL-23p19 mAb-treated mice. Analysis of lymph node cells and CNS-infiltrating cells showed little or no difference in the number of $\mathrm{CD}^{+}{ }^{+} \mathrm{CD} 25^{+} \mathrm{FoxP} 3{ }^{+}$cells in anti-IL-23p19 or isotype control mAb-treated mice (data not shown). Passive transfer of cells isolated from anti-p19-treated mice to PLP peptide-immunized mice did not confer protection from EAE, suggesting that anti-IL-23p19 treatment in the SJL model of EAE did not increase the number of FoxP3 ${ }^{+}$Tregs capable of inhibiting EAE relapse. 
A
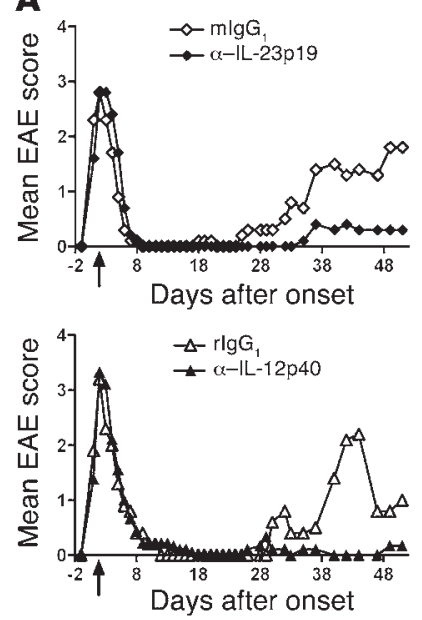
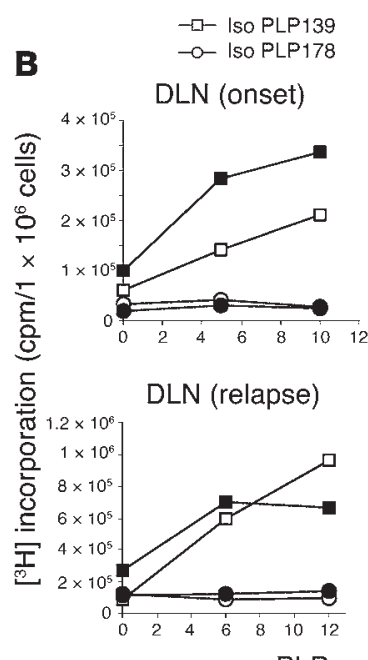

PLP peptide $(\mu \mathrm{g} / \mathrm{ml})$

\section{Figure 5}

Anti-IL-23 therapy inhibits PLP epitope spreading and relapsing EAE. (A) Average clinical score of mice treated with anti-IL-23p19 (clone MB490) or anti-p40 antibody on the day of EAE onset. The first antibody dose was given by the i.v. route at the first sign of clinical disease and the 2 subsequent doses by the s.c. route at days 7 and 14 after EAE onset. One of 3 experiments is shown. Disease relapse incidence and histopathology scores are shown in Table 3. Arrows indicate the day of initial mAb treatment (day of disease onset). (B) Epitope spreading was determined by analysis of DLN cells or purified CNS mononuclear cells for response to PLP P $_{139-151}$ or PLP $_{178-191}$ on either the day of disease onset or during disease relapse. Purified CNS mononuclear cells from mice treated with anti-IL-23p19 or isotype control mAbs were stimulated for 4 days with PLP peptides then pulsed with ${ }^{3}[\mathrm{H}] 16$ hours before proliferation assay. Cells from 3 to 4 mice of each treatment group were pooled and cultured at indicated PLP peptide concentration in triplicate wells. Results from 1 of 2 experiments are shown.

Thus, these studies suggest that anti-IL-23p19 therapeutic inhibition of EAE relapse is mainly due to inhibition of encephalitogenic epitope spreading and recruitment of newly activated pathogenic T cells, possibly from the naive thymic emergent pool.

Other mechanisms of action of anti-IL-23p19 therapy are reducing the number of inflammatory myeloid cells invading the CNS and dampening the levels of monokines derived from macrophage and dendritic cells (e.g., IL-1, IL-6, TNF, MCP-1, MDC, CXCL1, CXCL2, CCR1, MHC class II, CD11b, Mac 2, F4/80, CD86, CD14, TREM1, MYD88, and NADPhox gp91). This myeloid cell invasion and the production of proinflammatory mediators are the driving forces behind CNS edema and demyelination - the pathological hallmarks of EAE and MS. Recent studies have demonstrated that the IL-23 receptor complex is expressed on a subset of inflammatory macrophages and dendritic cells (22). IL-23 can induce ex vivo production of IL-1 and TNF by peritoneal macrophage (23) and enhance DTH responses mediated by the passive transfer of peptide-pulsed dendritic cells (47). The direct effect of IL-23 on myeloid cell function was confirmed by our recent study demonstrating that anti-IL-23p19 treatment of T cell-deficient Rag KO mice completely prevented colitis induced by activated dendritic cells and macrophages (D.J. Cua and B. Mckenzie, unpublished observations). In addition, this myeloid cell-mediated colitis was only inducible in IL-12p35 $\times$ Rag double-KO mice but not IL-23p19 $\times$ Rag KO mice. This T cell-independent colitis model showed that IL-23 but not IL-12 directly regulates the capacity of dendritic cells to induce inflammatory bowel disease-like lesions. These findings have important implications as both Th1
- Anti-p19 PLP139

- Anti-p19 PLP178

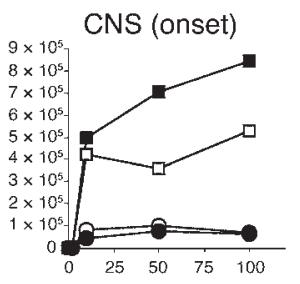

CNS (relapse)

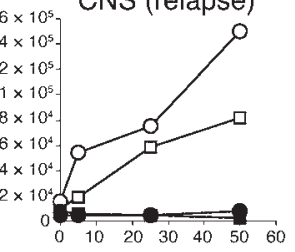

and $\mathrm{Th}_{\mathrm{IL}-17}$ cells can initiate CNS autoimmune pathologies, yet IL-23p19- but not IL-12p35-deficient mice remain fully resistant to EAE. This indicates that 1 of the key differences of IL-12 versus IL-23 contribution to autoimmunity lies within the myeloid compartment. The current hypothesis is that the combined actions of IL-23 on Th $\mathrm{IL}_{\mathrm{IL}-17}$ cells as well as dendritic cells and/or macrophages shape the role of IL-23 in immunopathology.

We have demonstrated that antiIL-23p19 therapy is as effective as antip40 therapy for treatment of autoimmune inflammation of the brain. There was no difference in blocking IL-23 alone or blocking both IL-12 and IL-23 for the treatment of acute or relapsing EAE. One concern with targeting these potent immune regulatory cytokines for treating patients with autoimmune diseases is the potential risk of infections and tumor development. While IL-12 is an important cytokine for host defense and immune surveillance, the precise role of IL-23 in host protection is not yet known. Recent studies have indicated that resistance to different types of infections may require different cell-mediated immune responses associated with IL-12 or IL-23. Indeed, IL-23-deficient mice are resistant to Toxoplasma, Mycobacterium, Listeria, and Leishmania infections whereas p35- or p40-deficient mice, which lack IL-12, are very susceptible to these pathogens $(48,49)$ (D.J. Cua, unpublished observations). However, other studies have indicated that resistance to Klebsiella pneumoniae infections may require the IL-23/IL-17 immune pathway. IL-17R-deficient mice are highly susceptible to Klebsiella pneumoniae. Infecting mice lacking IL-17R with Klebsiella pneumoniae caused acute bacteremia and early death, associated with a delay in neutrophil recruitment (50, 51). Anti-IL-17 administration prevented neutrophil accumulation in the lung following pulmonary LPS challenge (52). In addition, administration of anti-IL-23p19 mAbs reduced LPS induction of IL-17 and lowered the number of circulating neutrophil (D.J. Cua, unpublished observations), consistent with the recently described neutrophil turnstile hypothesis proposed by Ley and coworkers (53), which suggests that the IL-23/IL-17 immune axis is important for maintenance of neutrophil homeostasis. Thus, targeting IL-12 could affect IFN- $\gamma$-mediated macrophage and CTL activation as well as induction of subclasses of antibody responses important for host defense. In contrast, targeting IL-23 will likely affect IL-17-dependent rapid neutrophil recruitment to sites of injury and inflammation.

It is well recognized that anti-p40 treatment is highly efficacious for inflammatory autoimmune disease models. Recent clinical data also indicate that anti-p40 therapy may be effective for the treatment of human autoimmune diseases such as psoriasis and Crohn disease $(54,55)$. One potential issue with anti-p40 therapy is that it may inhibit both the classical IL-12/IFN- $\gamma$ and the newly described IL-23/IL-17 immune pathways as discussed above. Con- 
Table 3

Anti-IL-23p19 therapeutic treatment inhibits EAE relapse

\begin{tabular}{|c|c|c|c|c|}
\hline & \multicolumn{3}{|c|}{ Relapse Clinical EAE } & \multirow{2}{*}{$\begin{array}{l}\text { Histological EAE } \\
\text { Mean no. of } \\
\text { inflammatory foci }\end{array}$} \\
\hline & $\begin{array}{c}\text { Relapse } \\
(\%)\end{array}$ & $\begin{array}{l}\text { Mean day } \\
\text { of relapse }\end{array}$ & $\begin{array}{l}\text { Mean maximal } \\
\text { relapse score }\end{array}$ & \\
\hline \multicolumn{5}{|c|}{ Treatment on the day of onset } \\
\hline Anti-IL-23p19 & $3 / 9(33 \%)$ & $40.33 \pm 4.37$ & $0.56 \pm 0.33$ & $20.67 \pm 2.91^{A}$ \\
\hline $\mathrm{mlg}_{1}$ & $7 / 8(88 \%)$ & $33.43 \pm 3.72$ & $2.63 \pm 0.56$ & $68.4 \pm 8.61$ \\
\hline Anti-IL-12p40 & $2 / 9(22 \%)$ & $27.0 \pm 1.0$ & $0.33 \pm 0.24$ & $10.67 \pm 1.76^{B}$ \\
\hline $\mathrm{rlg}_{2 \mathrm{a}}$ & $4 / 5(80 \%)$ & $39.5 \pm 4.37$ & $2.4 \pm 1.12$ & $43.33 \pm 8.97$ \\
\hline \multicolumn{5}{|c|}{ Treatment during remission } \\
\hline Anti-IL-23p19 & $2 / 11(18 \%)$ & $40.5 \pm 13.5$ & $0.64 \pm 0.47$ & $13.57 \pm 5.14 \mathrm{C}$ \\
\hline$m \lg G_{1}$ & $8 / 10(80 \%)$ & $28.5 \pm 2.43$ & $2.9 \pm 0.62$ & $79.64 \pm 20.74$ \\
\hline Anti-IL-12p40 & $2 / 13(15 \%)$ & $47.0 \pm 7.0$ & $0.46 \pm 0.31$ & $29.71 \pm 20.00^{D}$ \\
\hline $\mathrm{rlg}_{2 \mathrm{a}}$ & $10 / 11(91 \%)$ & $34.6 \pm 1.46$ & $4.0 \pm 0.47$ & $129.67 \pm 27.60$ \\
\hline Anti-IL-17 & $7 / 13(54 \%)$ & $46.86 \pm 1.61$ & $1.92 \pm 0.65$ & $74.63 \pm 24.92^{\mathrm{E}}$ \\
\hline $\mathrm{rlg}_{1}$ & $7 / 7(100 \%)$ & $26.0 \pm 1.39$ & $4.6 \pm 0.80$ & $87.67 \pm 17.73$ \\
\hline
\end{tabular}

Mice were immunized with $\mathrm{PLP}_{139-151}$ and treated with pertussis toxin at day 0 . Mice received $\mathrm{mAb}$ treatment on the day of clinical paralysis onset or during remission from acute disease. Assessment of relapse clinical EAE includes the number of mice that develop disease relapse, the mean day of relapse onset among mice with clinical relapse \pm SEM, and the mean clinical disease grade \pm SEM of each treatment group. Spinal cord samples for histopathology were taken on days 52-54. Data shown are mean number of parenchymal and perivascular inflammatory foci \pm SD. ${ }^{A} P<0.006$, comparing anti-IL-23p19 versus $\mathrm{mlgG}_{1}$ by 2 -tailed Student's $t$ test; ${ }^{B} P<0.02$, comparing anti-IL-12p40 versus rlgG ${ }_{2 a}$ by Student's $t$ test; ${ }^{c} P<0.02$, comparing anti-IL-23p19 versus $\mathrm{mlgG}_{1}$ by Student's $t$ test; ${ }^{D} P<0.01$, comparing anti-IL-12p40 versus rlgG $\mathrm{G}_{2 \mathrm{a}}$ by Student's $t$ test; ${ }^{\mathrm{E} P}<0.69$, comparing anti-IL-17 versus rlgG 1 by Student's $t$ test.
Institutional Animal Care and Use Committee or the University of Pennsylvania, in accordance with the American Association for Accreditation of Laboratory Animal Care International.

EAE. Female SJL mice (8-12 weeks old) were immunized subcutaneously with 80 $\mu \mathrm{g}$ of PLP PL-151 $_{139}$ peptide (Bio-Synthesis Inc.) emulsified in CFA supplemented with $2 \mathrm{mg} / \mathrm{ml}$ of Mycobacterium tuberculosis (BD Diagnostics - Difco). The mice received $100 \mathrm{ng}$ of pertussis toxin i.v. (List Biological Laboratories Inc.) at the time of immunization. Clinical disease onset occurred from days 8-10 after immunization. Clinical status of mice was evaluated as follows: grade 0 , normal; grade 1 , limp tail; grade 2, hind limb weakness; grade 3 , inability to right and hind limb paresis; grade 4, single hind limb paralysis; grade 5, bilateral hind limb paralysis; and grade 6 , moribund. For histopathology, mice were euthanized with $\mathrm{CO}_{2}$. The spinal cords were removed and embedded in paraffin. Sections of $5 \mu \mathrm{m}$ were stained with H\&E.

Generation of anti-IL-23p19 mAbs. IL$23 \mathrm{p} 19^{-/-}$mice were immunized with $25-50$ sequently, anti-p40 therapy may affect a broad range of immune responses. Studies in the mouse suggest that specific inhibition of the IL-23/IL-17 immune axis is sufficient to block organ-specific autoimmune inflammation. If the IL-23/IL-17 immune pathway operates in humans as in mice, then specific blockade of the IL-23 immune pathway may be an effective and safer therapy for immune-mediated inflammatory diseases.

\section{Methods}

Mice. Female SJL, C57BL/6, and T-bet-deficient mice on the C57BL/6 background were obtained from Jackson Laboratory. Stat-1 KO mice on the C57BL/ 6 background were originally obtained from David Levy (New York University School of Medicine, New York, New York, USA). All animal procedures were approved by the DNAX Research Inc.

\section{Figure 6}

Anti-IL-23 therapy during disease remission inhibits CNS expression of proinflammatory cytokines and prevents EAE relapse. (A) Average clinical score of mice given the first treatment dose of anti-IL-23p19 (clone MB490), anti-IL-17 (clone 1D10), or anti-p40 (clone C17.8) during disease remission. The first antibody dose (1 $\mathrm{mg}$ ) was given by the i.v. route at day 18 after immunization and the 2 subsequent doses ( $1 \mathrm{mg} /$ dose) by the s.c. route at 7 and 14 days after the initial treatment. Results from 1 of 2 experiments are shown. Details on incidence of disease relapse and histopathology scores are shown in Table 3. Arrows indicate day of initial mAb treatment (during disease remission). (B) Quantitative analysis of proinflammatory gene expression levels of spinal cords taken at peak disease relapse of the isotype control groups (day 30-40 after immunization). Note the $\log _{10}$ scale on the $x$ axis. Error bars show SD of 4-5 representative animals from each treatment group. TaqMan gene expression results were normalized to ubiquitin, a housekeeping gene. Results are representative of 2 experiments. OPN, osteopontin.

$\mu \mathrm{g}$ of recombinant murine IL-23 in CFA i.p. $(\times 1)$; IL-23 in IFA i.p. $(\times 3)$; and IL-23 in PBS i.v. $(\times 4)$ over a 6 -month period. The animals were sacrificed and hybridomas created by fusion with the mouse myeloma SP2/0 (ATCC). Hybridomas were cloned and screened for anti-p19 reactivity and then counter-screened for absence of anti-p40 reactivity by ELISA.
A
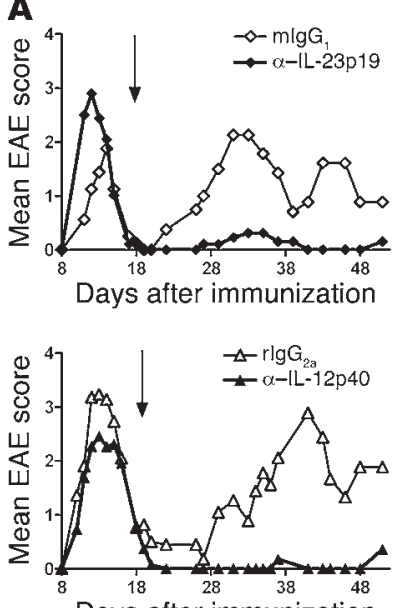

Days after immunization

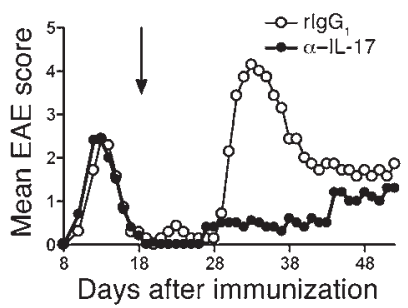

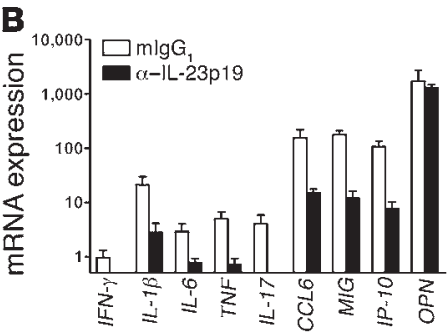
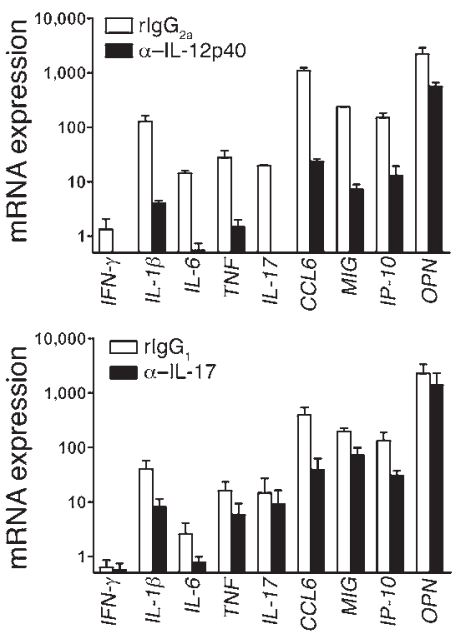
Anti-IL-23p19 reactive mAbs were screened for antagonist activity by a $\mathrm{Ba} / \mathrm{F} 3-\mathrm{IL}-23 \mathrm{R}-\mathrm{Fas}$ assay. Ba/F3 cells expressing the extracellular domain of murine IL-23R fused to the intracellular domain of murine Fas were treated with a fixed concentration of recombinant murine IL-23 protein. IL-23 binding to Ba/F3-IL-23R-Fas cells induced Fas signaling, resulting in cell death measured by Alamar Blue incorporation assays. Two antagonist IL-23 mAbs were used in this work (clone MB74 and MB490). Further in vivo assays confirmed that these anti-IL-23p19 mAbs inhibited IL-23-dependent serum IL-17 production and neutrophilia but not IL-12-dependent IFN- $\gamma$ production.

Anti-cytokine treatment of EAE. SJL mice were treated with indicated doses of anti-IL-23p19 (clone MB74 or clone MB490, mouse IgG1), antiIL-12p40 (clone C17.8, rat IgG2a), anti-IL-17 (clone 18H10 and clone $1 \mathrm{D} 10$ rat IgG1), anti-IFN- $\gamma$ (clone XMG1.2, rat IgG1), or relevant isotype controls during the course of EAE. All anti-cytokine antibodies were generated at DNAX Research Inc. with less than $4 \mathrm{EU} / \mathrm{mg}$ of mAbs. Anti-IL-17, anti-IL-12p40, and anti-IFN- $\gamma$ mAbs were also obtained from BD Biosciences - Pharmingen, SouthernBiotech, and Upstate USA Inc.

Isolation of CNS-infiltrating cells and CNS antigen-specific proliferative response. Mice were perfused via the left atria with glucose containing PBS and the brain and spinal cord removed. $\mathrm{T}$ cells, macrophages, and microglia were isolated by digestion of the brain and spinal cord homogenate with collagenase and DNAse, followed by Percoll gradient centrifugation (28). CNS homogenates were pooled for each treatment group prior to analysis. In the CNS, the number of CD $45^{\text {hi }} \mathrm{CD} 4^{+} \mathrm{T}$ cells, $\mathrm{CD} 45^{\mathrm{hi}} \mathrm{CD} 11 \mathrm{~b}^{+} \mathrm{CD} 4^{-}$inflammatory macrophages, and $\mathrm{CD} 45^{1 \circ} \mathrm{CD} 11 \mathrm{~b}^{+} \mathrm{CD} 4^{-}$resident microglia was determined by surface staining with antibodies against CD11b-FITC, CD4$\mathrm{PE}$, and CD45-APC, then multiplying the frequency of each population by the total number of cells isolated per treatment group.

CNS or DLN cell suspensions were cultured at 2 to $5 \times 10^{5}$ cells per well in a final volume of $200 \mu \mathrm{l}$ RPMI-10 in round-bottomed 96-well plates (Costar; Corning Inc.). Cells were stimulated with indicated quantity of PLP $_{139-151}$ or PLP ${ }_{178-191}$ for 96 hours and pulsed with $2 \mu \mathrm{Ci}$ of $\left[{ }^{3} \mathrm{H}\right] \mathrm{TdR}$ per well for the last 16 hours of culture. Incorporation was measured by liquid scintillation spectroscopy and data are expressed as mean count per minute of triplicate wells.

Intracellular cytokine flow cytometry and cytokine ELISA. Isolated CNSinfiltrating cells were stimulated with $50 \mathrm{ng} / \mathrm{ml}$ PMA and $500 \mathrm{ng} / \mathrm{ml}$ ionomycin (Sigma-Aldrich) in the presence of GolgiPlug (BD Biosciences) for 4 hours, prior to intracellular cytokine staining. Cells were surface stained with anti-CD4-FITC in the presence of Fc-blocking antibodies. Then they were washed, fixed, and permeabilized with Cytofix/Cytoperm buffer and intracellular cytokines were stained with antibodies against IL-17-PE and IFN- $\gamma$-APC (BD Biosciences). T-bet was detected using mAb clone 4B10 from Santa Cruz Biotechnology Inc., and TIM3 was detected using $\mathrm{mAb}$ clone 8B.2C12 from eBioscience. Samples were read using a FACScalibur flow cytometer and data analyzed using Cytomics version 2 (Beckman Coulter).

For serum cytokine ELISA, blood was taken during the course of EAE via the tail vein, and serum samples were prepared using Z-Gel Micro Tubes (Sarstedt). Mouse IL-17 was detected with Quantikine Immunoassay kit (R\&D Systems) or in-house ELISA assays.
IL-17 production of Stat-1 $1^{-/}$, T-bet ${ }^{-/}$, and WT C57BL/6 mice. Naive lymph node cells were plated at a density of $4 \times 10^{5}$ cells per well in a final volume of $200 \mu \mathrm{l}$ in round-bottomed 96-well plates (Costar; Corning Inc.). The cells were stimulated with soluble anti-CD3 antibody $(1 \mu \mathrm{g} / \mathrm{ml}$ ) (clone 145-2C11, prepared from hybridomas) in the presence or absence of IL-23 $(10 \mathrm{ng} / \mathrm{ml})$. The plates were incubated at $37^{\circ} \mathrm{C}$ in $5 \% \mathrm{CO}_{2}$ for 48 hours. IL-17 levels in the culture supernatant were measured by ELISA after the 48-hour incubation period.

Real-time quantitative PCR for gene expression. For TaqMan analysis, total RNA was isolated using RNA STAT60 (Tel-Test Inc.) according to manufacturer's instructions. After isopropanol precipitation, total RNA was reextracted with phenol/chloroform/isoamyl alcohol (25:24:1) (Sigma-Aldrich) using Phase Lock light tubes (Eppendorf). Total RNA $(5 \mu \mathrm{g})$ was subjected to treatment with DNase (Roche Molecular Biochemicals) according to manufacturer's instructions to eliminate possible genomic DNA contamination. DNase-treated total RNA was reverse-transcribed using Superscript II (Invitrogen Corp.) according to manufacturer's instructions. Primers were designed using Primer Express (Applied Biosystems) or obtained commercially from Applied Biosystems. Real-time quantitative PCR on $10 \mathrm{ng}$ of cDNA from each sample was performed using either of 2 methods. In the first method, 2 gene-specific unlabeled primers were utilized at $400 \mathrm{nM}$ in a PerkinElmer SYBR green real-time quantitative PCR assay utilizing an ABI 5700 instrument. In the second method, 2 unlabeled primers at $900 \mathrm{nM}$ each were used with $250 \mathrm{nM}$ of FAM-labeled probe (Applied Biosystems) in a TaqMan real-time quantitative PCR reaction on an ABI 7700 sequence detection system. The absence of genomic DNA contamination was confirmed using primers that recognize the genomic region of the CD4 promoter. Ubiquitin levels were measured in a separate reaction and used to normalize the data. Using the mean cycle threshold $(\mathrm{Ct})$ value for ubiquitin and the gene of interests for each sample, the equation 1.8 (Ct ubiquitin minus $C t$ gene of interest) $\times 10^{4}$ was used to obtain the normalized values.

Statistics. Two-tailed Student's $t$ test was used to analyze the significance of results. In addition, Mann-Whitney $U$ test was performed for nonparametric analyses. Differences were considered significant at $P \leq 0.05$.

\section{Acknowledgments}

We want to thank M. Bigler and S. Chen for screening and generation of anti-IL-23p19 and anti-IL-17 mAbs, E. Murphy for RNA isolation, and N. Nguyen for cell-based screening assays. We also thank B. Coffman, S. Stohlman, M. Oft, and E. Bowman for helpful discussions.

Received for publication May 11, 2005, and accepted in revised form January 17, 2006.

Address correspondence to: Daniel J. Cua, Schering-Plough Biopharma, DNAX, 901 California Avenue, Palo Alto, California 94304, USA. Phone: (650) 496-1261; Fax: (650) 496-1200; E-mail: daniel.cua@dnax.org.

The research was carried out at DNAX, which is now ScheringPlough Biopharma.
1. Martino, G., and Hartung, H.P. 1999. Immunopathogenesis of multiple sclerosis: the role of $\mathrm{T}$ cells. Curr. Opin. Neurol. 12:309-321.

2. Behi, M.E., et al. 2005. New insights into cell responses involved in experimental autoimmune encephalomyelitis and multiple sclerosis. Immunol. Lett. 96:11-26.

3. O'Garra, A., and Arai, N. 2000. The molecular basis of $\mathrm{T}$ helper 1 and $\mathrm{T}$ helper 2 cell differentiation.
Trends Cell Biol. 10:542-550.

4. Shtrichman, R., and Sanuel, C.E. 2001. The role of gamma interferon in antimicrobial immunity. Curr. Opin. Microbiol. 4:251-259.

5. Airoldi, I., et al. 2004. The IL-12R $\beta 2$ gene functions as a tumor suppressor in human B cell malignancies. J. Clin. Invest. 113:1651-1659. doi:10.1172/ JCI200420303.

6. Leonard, J.P., Waldburger, K.E., and Goldman, S.J.
1995. Prevention of experimental autoimmune encephalomyelitis by antibodies against interleukin 12. J. Exp. Med. 181:381-386.

7. Ichikawa, M., et al. 2000. Anti-IL-12 antibody prevents the development and progression of multiple sclerosis-like relapsing-remitting demyelinating disease in NOD mice induced with myelin oligodendrocyte glycoprotein peptide. J. Neuroimmunol. 102:56-66. 
8. Constantinescu, C.S., et al. 1998. Antibodies against IL-12 prevent superantigen-induced and spontaneous relapses of experimental autoimmune encephalomyelitis. J. Immunol. 161:5097-5104.

9. Trembleau, S., Germann, T., Gately, M.K., and Adorini, L. 1995. The role of IL-12 in the induction of organ-specific autoimmune diseases. Immunol. Today. 16:383-386.

10. Adorini, L., Guery, J.C., and Trembleau, S. 1996. Manipulation of the Th1/Th2 cell balance: an approach to treat human autoimmune diseases? Autoimmunity. 23:53-68.

11. Leonard, J.P., Waldburger, K.E., and Goldman, S.J. 1996. Regulation of experimental autoimmune encephalomyelitis by interleukin-12. Ann. N.Y. Acad. Sci. 795:216-226.

12. McIntyre, K.W., et al. 1996. Reduced incidence and severity of collagen-induced arthritis in interleukin12-deficient mice. Eur. J. Immunol. 26:2933-2938.

13. Malfait, A.M., et al. 1998. Blockade of IL-12 during the induction of collagen-induced arthritis (CIA) markedly attenuates the severity of the arthritis. Clin. Exp. Immunol. 111:377-383.

14. Ferber, I., et al. 1996. Mice with a disrupted IFNgamma gene are susceptible to the induction of experimental autoimmune encephalomyelitis (EAE). J. Immunol. 156:5-7.

15. Willenborg, D.O., Fordham, S., Bernard, C.C., Cowden, W.B., and Ramshaw, I.A. 1996. IFN gamma plays a critical down-regulatory role in the induction and effector phase of myelin oligodendrocyte glycoprotein-induced autoimmune encephalomyelitis. J. Immunol. 157:3223-3227.

16. Zhang, G., et al. 2003. Induction of experimental autoimmune encephalomyelitis in IL-12 receptor-beta 2-deficient mice: IL-12 responsiveness is not required in the pathogenesis of inflammatory demyelination in the central nervous system. J. Immunol. 170:2153-2160.

17. Becher, B., Durell, B.G., and Noelle, R.J. 2002. Experimental autoimmune encephalitis and inflammation in the absence of interleukin-12. J. Clin. Invest. 110:493-497. doi:10.1172/JCI200215751.

18. Gran, B., et al. 2002. IL-12p35-deficient mice are susceptible to experimental autoimmune encephalomyelitis: evidence for redundancy in the IL-12 system in the induction of central nervous system autoimmune demyelination. J. Immunol. 169:7104-7110.

19. Bettelli, E., et al. 2004. Loss of T-bet, but not STAT1, prevents the development of experimental autoimmune encephalomyelitis. J. Exp. Med. 200:79-87.

20. Chitnis, T., et al. 2001. Effect of targeted disruption of STAT4 and STAT6 on the induction of experimental autoimmune encephalomyelitis. J. Clin. Invest. 108:739-747. doi:10.1172/JCI200112563.

21. Oppmann, B., et al. 2000. Novel p19 protein engages IL-12p40 to form a cytokine, IL-23, with biological activities similar as well as distinct from IL-12. Immunity. 13:715-725.

22. Parham, C., et al. 2002. A receptor for the heterodimeric cytokine IL-23 is composed of IL-12Rbeta1 and a novel cytokine receptor subunit, IL-23R. J. Immunol. 168:5699-5708.
23. Cua, D.J., et al. 2003. Interleukin-23 rather than interleukin-12 is the critical cytokine for autoimmune inflammation of the brain. Nature. 421:744-748.

24. Murphy, C.A., et al. 2003. Divergent pro- and antiinflammatory roles for IL-23 and IL-12 in joint autoimmune inflammation. J. Exp. Med. 198:1951-1957.

25. Langrish, C.L., et al. 2005. IL-23 drives a pathogenic $T$ cell population that induces autoimmune inflammation. J. Exp. Med. 201:233-240.

26. Yen, D., et al. 2006. IL-23 is essential for T cellmediated colitis and promotes inflammation via IL-17 and IL-6. J. Clin. Invest. 116:1310-1316.

27. Brok, H.P., et al. 2002. Prevention of experimental autoimmune encephalomyelitis in common marmosets using an anti-IL-12p40 monoclonal antibody. J. Immunol. 169:6554-6563.

28. Sedgwick, J.D., et al. 1991. Isolation and direct characterization of resident microglial cells from the normal and inflamed central nervous system. Proc. Natl. Acad. Sci. U. S. A. 88:7438-7442.

29. Hickey, W.F. 1991. Migration of hematogenous cells through the blood-brain barrier and the initiation of CNS inflammation. Brain Pathol. 1:97-105.

30. Kennedy, M.K., Torrance, D.S., Picha, K.S., and Mohler, K.M. 1992. Analysis of cytokine mRNA expression in the central nervous system of mice with experimental autoimmune encephalomyelitis reveals that IL-10 mRNA expression correlates with recovery. J. Immunol. 149:2496-2505.

31. Refaeli, Y., Van Parijs, L., Alexander, S.I., and Abbas, A.K. 2002. Interferon gamma is required for activation-induced death of T lymphocytes. J. Exp. Med. 196:999-1005.

32. Monney, L., et al. 2002. Th1-specific cell surface protein Tim-3 regulates macrophage activation and severity of an autoimmune disease. Nature. 415:536-541.

33. McMahon, E.J., Bailey, S.L., Castenada, C.V., Waldner, H., and Miller, S.D. 2005. Epitope spreading initiates in the CNS in two mouse models of multiple sclerosis. Nat. Med. 11:335-339.

34. Langrish, C.L., et al. 2004. IL-12 and IL-23: master regulators of innate and adaptive immunity. Immunol. Rev. 202:96-105.

35. McKenzie, B.S., Kastelein, R.A., and Cua, D.J. 2005. Understanding the IL-23/IL-17 immune pathway. Trends Immunol. 27:17-23.

36. Harrington, L.E., et al. 2005. Interleukin 17-producing CD4+ effector $\mathrm{T}$ cells develop via a lineage distinct from the $\mathrm{T}$ helper type 1 and 2 lineages. Nat. Immunol. 6:1123-1132.

37. Park, H., et al. 2005. A distinct lineage of CD4 T cells regulates tissue inflammation by producing interleukin 17. Nat. Immunol. 6:1133-1141.

38. Afkarian, M., et al. 2002. T-bet is a STAT1-induced regulator of IL-12R expression in naive CD4+ T cells. Nat. Immunol. 3:549-557.

39. Lovett-Racke, A.E., et al. 2004. Silencing T-bet defines a critical role in the differentiation of autoreactive T lymphocytes. Immunity. 21:719-731.

40. Lugo-Villarino, G., Maldonado-Lopez, R., Possemato, R., Penaranda, C., and Glimcher, L.H. 2003. T-bet is required for optimal production of IFN-gamma and antigen-specific T cell activation by dendritic cells. Proc. Natl. Acad. Sci. U. S. A 100:7749-7754.

41. Gielen, A.W., et al. 2005. Expression of T cell immunoglobulin- and mucin-domain-containing molecules- 1 and -3 (TIM- 1 and - 3 ) in the rat nervous and immune systems. J. Neuroimmunol. 164:93-104.

42. Bettelli, E., and Kuchroo, V.K. 2005. IL-12- and IL-23induced T helper cell subsets: birds of the same feather flock together. J. Exp. Med. 201:169-171.

43. Hwang, E.S., Szabo, S.J., Schwartzberg, P.L., and Glimcher, L.H. 2005. T helper cell fate specified by kinase-mediated interaction of T-bet with GATA-3. Science. 307:430-433.

44. Billiau, A., et al. 1988. Enhancement of experimental allergic encephalomyelitis in mice by antibodies against IFN-gamma. J. Immunol. 140:1506-1510.

45. Muhl, H., and Pfeilschifter, J. 2003. Anti-inflammatory properties of pro-inflammatory interferongamma. Int. Immunopharmacol. 3:1247-1255.

46. Novelli, F., et al. 1997. Expression and role in apoptosis of the alpha- and beta-chains of the IFNgamma receptor on human Th1 and Th2 clones. J. Immunol. 159:206-213.

47. Belladonna, M.L., et al. 2002. IL-23 and IL-12 have overlapping, but distinct, effects on murine dendritic cells. J. Immunol. 168:5448-5454.

48. Khader, S.A., et al. 2005. IL-23 compensates for the absence of IL-12p70 and is essential for the IL-17 response during tuberculosis but is dispensable for protection and antigen-specific IFN-gamma responses if IL-12p70 is available. J. Immunol. 175:788-795.

49. Lieberman, L.A., et al. 2004. IL-23 provides a limited mechanism of resistance to acute toxoplasmosis in the absence of IL-12. J. Immunol. 173:1887-1893.

50. Happel, K.I., et al. 2003. Cutting edge: roles of Toll-like receptor 4 and IL-23 in IL-17 expression in response to Klebsiella pneumoniae infection: requirement of interleukin 17 receptor signaling for lung CXC chemokine and granulocyte colony-stimulating factor expression, neutrophil recruitment, and host defense. J. Immunol. 170:4432-4436.

51. Ye, P., et al. 2001. Requirement of interleukin 17 receptor signaling for lung CXC chemokine and granulocyte colony-stimulating factor expression, neutrophil recruitment, and host defense. J. Exp. Med. 194:519-527.

52. Miyamoto, M., et al. 2003. Endogenous IL-17 as a mediator of neutrophil recruitment caused by endotoxin exposure in mouse airways. J. Immunol. 170:4665-4672

53. Stark, M.A., et al. 2005. Phagocytosis of apoptotic neutrophils regulates granulopoiesis via IL-23 and IL-17. Immunity. 22:285-294.

54. Kauffman, C.L., et al. 2004. A phase I study evaluating the safety, pharmacokinetics, and clinical response of a human IL-12 p40 antibody in subjects with plaque psoriasis. J. Invest. Dermatol. 123:1037-1044.

55. Mannon, P.J., et al. 2004. Anti-interleukin-12 antibody for active Crohn's disease. N. Engl. J. Med. 351:2069-2079. 